\title{
Preventive Effects of Collagen Peptide from Deer Sinew on Bone Loss in Ovariectomized Rats
}

\author{
He Zhang, ${ }^{1,2}$ Ying Dong, ${ }^{1}$ Bin Qi, ${ }^{1}$ Li Liu, ${ }^{1}$ Guangxin Zhou, ${ }^{1}$ Xueyuan Bai, ${ }^{1}$ Chunhui Yang, \\ Daqing Zhao, ${ }^{1}$ and Yu Zhao ${ }^{1}$ \\ ${ }^{1}$ Changchun University of Chinese Medicine, Boshuo Road 1035, Changchun, Jilin 130117, China \\ ${ }^{2}$ The Affiliated Hospital to Changchun University of Chinese Medicine, Gongnong Road 1478, Changchun, Jilin 130021, China
}

Correspondence should be addressed to Daqing Zhao; zhaodaqing1963@163.com and Yu Zhao; cnzhaoyu@hotmail.com

Received 2 April 2014; Accepted 10 June 2014; Published 1 July 2014

Academic Editor: Tsung-Chieh Jackson Wu

Copyright (C) 2014 He Zhang et al. This is an open access article distributed under the Creative Commons Attribution License, which permits unrestricted use, distribution, and reproduction in any medium, provided the original work is properly cited.

\begin{abstract}
Deer sinew (DS) has been used traditionally for various illnesses, and the major active constituent is collagen. In this study, we assessed the effects of collagen peptide from DS on bone loss in the ovariectomized rats. Wister female rats were randomly divided into six groups as follows: sham-operated (SHAM), ovariectomized control (OVX), OVX given $1.0 \mathrm{mg} / \mathrm{kg} / \mathrm{week}$ nylestriol $(\mathrm{OVX}+\mathrm{N})$, OVX given $0.4 \mathrm{~g} / \mathrm{kg} /$ day collagen peptide $(\mathrm{OVX}+\mathrm{H})$, OVX given $0.2 \mathrm{~g} / \mathrm{kg} / \mathrm{day}$ collagen peptide $(\mathrm{OXV}+\mathrm{M})$, and OVX given $0.1 \mathrm{~g} / \mathrm{kg} /$ day collagen peptide $(\mathrm{OXV}+\mathrm{L})$, respectively. After 13 weeks of treatment, the rats were euthanized, and the effects of collagen peptide on body weight, uterine weight, bone mineral density (BMD), serum biochemical indicators, bone histomorphometry, and bone mechanics were observed. The data showed that BMD and concentration of serum hydroxyproline were significantly increased and the levels of serum calcium, phosphorus, and alkaline phosphatase were decreased. Besides, histomorphometric parameters and mechanical indicators were improved. However, collagen peptide of DS has no effect on estradiol level, body weight, and uterine weight. Therefore, these results suggest that the collagen peptide supplementation may also prevent and treat bone loss.
\end{abstract}

\section{Introduction}

Osteoporosis (OP) is a silent and potentially disabling skeletal disease. Postmenopausal women are at greatest risk for developing OP. The hallmark of menopause is a reduction in bone mass caused by an imbalance between bone resorption and formation due to loss of ovarian function [1]. The pathogenesis of postmenopausal osteoporosis involves the interplay of many factors, such as aging, genetic, environmental, hormonal, nutritional, and life style factors [2]. The more widely OP medications include estrogen, calcitonin [3], bisphosphonate [4], calcium [5], vitamin $\mathrm{D}_{3}$, and selective estrogen receptor modulators (SERMs) [6]; however, some medications of them have serious side effects [7]. Therefore, the interest to find effective and safe alternatives for the treatment of osteoporosis has grown in recent years.

Traditional Chinese medicines contain a number of active constituents, which have been used for centuries to treat bone disease. Because Chinese medicines have less side effects, which seem to be more suitable for a long-term medication, now Chinese researchers have studied the therapeutic effects on osteoporosis by traditional medicines which contain soy [8], epimedium [9], cortex eucommiae [10], radix dipsaci [11], fructus psoraleae [12], Rehmannia glutinosa [13, 14], Astragalus membranaceus [15], and so on.

Deer sinew (DS) is derived from limbs of Cervus nippon Temminck or Cervus elaphus Linnaeus, distributing mainly in China, Japan, and Russia. DS is one of the best known and highly valued food and medicine. According to Chinese Materia Medica, DS possesses the function of strengthening tendons and bones, nourishing the liver and kidney, benefiting yang, and expelling wind damp, for the treatment of arms and legs weakness, pain of waist and knees, and twitch; consumptive disease, dizziness, and epicophosis; cold intolerance; rheumatism arthritis joints pain, and so on. DS contains rich collagen with a content of $82.12 \%$ [16]. Collagen constitutes a family of proteins presenting in the extracellular matrices, taking up about $25 \%$ to $35 \%$ of the whole-body 
protein content; unfortunately, our body loses collagen at a rate of $1 \%$ per year, starting at the age of 25 [17]. It is ubiquitous that collagen is responsible for maintaining the structural integrity of vertebrates and many other multicellular organisms [18], such as skin, tendons, ligaments, and cartilage. The collagen peptides are extensive used as health food in Chinese drugstore. Some researchers reported that collagen peptides supplementation could strengthen skin elasticity [19], improve the bone density [20, 21], and alleviate some arthritis symptoms [22].

According to traditional Chinese medicine, collagen peptide is essential ingredients of DS and plays important roles in improving symptoms of the menopausal osteoporosis. Therefore, this study discusses whether the collagen peptide of DS prevents bone loss in ovariectomized rats.

\section{Methods}

2.1. Preparation of Collagen Peptide. Deer sinew (DS) of Cervus elaphus Linnaeus was purchased from a deer farm in Shuang Yang, Ji Lin, in November, 2010. As in previous studies the collagen peptide was obtained from DS [16]. The DS was made by steeping in $0.2 \%$ hydrochloric acid when material/liquid ratio was $1: 12(\mathrm{w} / \mathrm{v})$ for $48 \mathrm{~h}$ at room temperature. Then collagen of DS was extracted in boiling water, adjusted to $\mathrm{pH} 7.5$ with $\mathrm{NaOH}(0.5 \mathrm{~mol} / \mathrm{L})$. After adding trypsin (Beijing dingguo biotech Co., Ltd) to collagen solution (enzyme: collagen $=1: 1000, \mathrm{w} / \mathrm{w}$ ), the reaction mixture was incubated at $37^{\circ} \mathrm{C}$ for $3 \mathrm{~h}$. To stop the reaction, the mixture was heated immediately at $100^{\circ} \mathrm{C}$ for $20 \mathrm{~min}$ and then centrifuged at $4000 \times \mathrm{g}$ for $30 \mathrm{~min}$, and the supernatant was freeze-dried. The powder of the water-solubilized extract was collagen peptide. The molecular weight of collagen peptide was assayed with HPLC, retention times of collagen peptide using Zenix SEC-100 $(7.8 \times 300 \mathrm{~mm}, 3 \mu \mathrm{m})$ column for analysis. Elution buffer, $0.1 \mathrm{M}$ phosphate buffer containing $0.1 \mathrm{M} \mathrm{Na}_{2} \mathrm{SO}_{4}, \mathrm{pH} 6.8$, flow rate was $0.5 \mathrm{~mL} / \mathrm{min}$ and detection wavelength was $230 \mathrm{~nm}$. The filtration calibration kits (LMW and HMW) were purchased from GE Healthcare. Protein concentration was measured by Lowry method using a protein assay kit (Beijing dingguo biotech Co., Ltd) that was around $72.25 \%$.

2.2. Amino Acid Analysis. Collagen peptide was hydrolyzed under vacuum in $6 \mathrm{~mol} / \mathrm{L} \mathrm{HCl}$ for $24 \mathrm{~h}$ at $110 \pm 1^{\circ} \mathrm{C}$ for general amino acid analysis. Amino acids converted to phenyl isothiocyanate (PITC) derivatives were analyzed by high performance liquid chromatography (HPLC) (Agilent 1100 series; Agilent Technologies, USA) with Wondasil-C18 (4.6× $150 \mathrm{~mm}, 5 \mu \mathrm{m})$. Eluents were $97 \%$ aqueous acetonitrile containing $0.1 \mathrm{~mol} / \mathrm{L}$ sodium acetate (pH6.5, eluent $\mathrm{A}$ ) and $80 \%$ aqueous acetonitrile (eluent $\mathrm{B}$ ); flow rate was $1.0 \mathrm{~mL} / \mathrm{min}$; the detection wavelengths were at $254 \mathrm{~nm}$ and the column temperature was $37^{\circ} \mathrm{C}$. The gradient elution procedures are ignored.

2.3. Animals and Treatments. Sixty female Wister rats which aged 10 weeks $(210 \pm 20 \mathrm{~g})$ were purchased by Basic Medical
Experimental Animal Center of Jilin University (Jilin, China, SCXK-JI-2008-0005) and acclimated to conditions for 1 week before the experiment. The rats were housed in an air-conditioned room with 12-hour light-dark illumination cycles and given free access to deionized water and food (commercial laboratory rat's food containing $22.0 \%$ protein, $7.90 \%$ fat, $3.0 \%$ fiber, $1.19 \%$ calcium, and $0.86 \%$ phosphorus) (Beijing Keaoxieli Fodder Co. Ltd, Beijing, China). At 11 weeks of age, the animals were either bilateral ovariectomized or sham operated (SHAM). One week after surgery, they were equally divided into six groups: SHAM, ovariectomized control (OVX), OVX given $1.0 \mathrm{mg} / \mathrm{kg} /$ week nylestriol (OVX $+\mathrm{N}$ ) (nylestriol tables were purchased from Shanghai New Hualian Pharmaceutical Co., Ltd, Shanghai, China), OVX given $0.4 \mathrm{~g} / \mathrm{kg} /$ day collagen peptide $(\mathrm{OVX}+\mathrm{H})$, OVX given $0.2 \mathrm{~g} / \mathrm{kg} /$ day collagen peptide $(\mathrm{OXV}+\mathrm{M})$, and OVX given $0.1 \mathrm{~g} / \mathrm{kg} /$ day collagen peptide $(\mathrm{OXV}+\mathrm{L})$, respectively. The SHAM and OVX were given oral gavages of deionized water. The nylestriol tables and collagen peptide were dissolved in deionized water. Then, they were given to the rats via oral gavage. The nylestriol group acted as positive control. These rats were administrated for 13 weeks. The body weight of each animal was measured weekly, and the dosage of drug administered was calculated based on the most recent body weight measurement. This experiment was approved by the Bioethics Committee of the Chang Chun University of Chinese Medicine, and the procedures of the experiment strictly adhered to generally accepted international rules and regulations.

2.4. Sample Collection. After 13 weeks of drug treatment, the experimental rats were fasted for $24 \mathrm{~h}$ and anesthetized. Blood samples were collected from the abdominal artery and centrifuged at $6000 \times \mathrm{g}$ for $10 \mathrm{~min}$; then, serum samples were stored at $-80^{\circ} \mathrm{C}$ for biochemical determinations. The left femurs were dissected, then placed in physiologic saline, and stored at $-20^{\circ} \mathrm{C}$ for measurement of bone mineral density (BMD) and bone mechanics indicators [23]. The right tibia and lumbar vertebrae were removed and fixed in 10\% neutralbuffered formalin for measuring of bone histomorphometry parameters. The uterus was removed from each rat, cleaned of adhering soft tissues, and immediately weighed.

2.5. Serum Biochemical Analysis. The concentrations of serum calcium (Ca) and phosphorus (P), alkaline phosphatase (ALP), and hydroxyproline (Hyp) were measured on an automatic chemistry analyzer (OLYMPUS 2700, Japan) using determination kit. The levels of serum estradiol $\left(\mathrm{E}_{2}\right)$ were measured by ELISA kit. These kits were purchased from BioSino Bio-technology and Science Inc. (Beijing, China).

2.6. Bone Mineral Density Analysis. The left femur was thawed for $12 \mathrm{~h}$ before the experiments and kept wrapped in gauze soaked with a $0.9 \%$ saline solution. The bone mineral density $\left(\mathrm{BMD}, \mathrm{cm}^{2}\right.$ ) of the distal one third of left femur was measured by single-energy X-ray densitometry (Model HH6005, Beijing Hehai Advanced Technology Co., Ltd., China). 
TABLE 1: Molecular size distributions with HPLC of collagen peptide.

\begin{tabular}{lccccccc}
\hline Number & $\begin{array}{c}\text { Retention time } \\
(\mathrm{min})\end{array}$ & $\begin{array}{c}\text { Molecular weight } \\
(\mathrm{Da})\end{array}$ & $\begin{array}{c}\text { Peak area } \\
\text { percentage }(\%)\end{array}$ & Number & $\begin{array}{c}\text { Retention time } \\
(\mathrm{min})\end{array}$ & $\begin{array}{c}\text { Molecular weight } \\
(\mathrm{Da})\end{array}$ & $\begin{array}{c}\text { Peak area } \\
\text { percentage (\%) }\end{array}$ \\
\hline 1 & 12.37 & 367553 & 35.38 & $1^{\prime}$ & 12.31 & 377016 & 0.59 \\
2 & 17.80 & 36829 & 29.13 & $2^{\prime}$ & 15.29 & 106669 & 3982 \\
3 & 19.07 & 21504 & 5.26 & $3^{\prime}$ & 23.05 & & \\
4 & 19.58 & 17325 & 24.99 & & & & \\
5 & 24.80 & 1897 & 4.38 & & & & \\
6 & 28.62 & 376 & 0.86 & & & & \\
\hline
\end{tabular}

2.7. Bone Mechanics Indicators Evaluation. The bone mechanics indicators of left femur were assessed by using a universal testing machine (Model AG-107A, Shimadzu, Japan). The fulcrum span of experimental parameter was $20 \mathrm{~mm}$; the loading speed was $2 \mathrm{~mm} / \mathrm{min}$. The test program interrupted the test at the specimen's breaking point. The stress, strain, and load parameters were recorded by the software. The maximum load $\left(L_{\max }\right)$, maximum deflection $\left(D_{\max }\right)$, maximum bending moment $\left(B_{\max }\right)$, and bone stress $(\sigma)$ were calculated.

2.8. Bone Histomorphometric Studies. The right tibia and lumbar vertebrae were fixed in $10 \%$ neutral formalin solution followed by decalcification with formic acid, dehydrated in increasing gradients of alcohol, cleared with xylene, and embedded in paraffin. The paraffin embedded tissues were cut into 5-micron sections with a microtome. Hematoxylin and eosin staining were performed and observed by light microscope (Model BX51, OLYPUS, Japan). Histomorphometry of the trabecular bone of tibia and lumbar vertebra was done by using an image analysis system. The parameters measured in this study were trabecular bone volume, trabecular thickness, trabecular number, and trabecular separation. Trabecular numbers (Tb.N, $n$ ), trabecular thickness (Tb.Th, $\mu \mathrm{m})$, trabecular separation (Tb.Sp, $\mu \mathrm{m}$ ), trabecular bone volume (BV/TV, \%), and cortical bone thickness (Cb.Th, $\mu \mathrm{m})$ were calculated [24].

2.9. Statistical Analysis. The results were presented as mean $\pm \mathrm{SD}$, and one-way analysis of variance followed by Dunnett's $t$-test were used for statistical analysis (PASW 19.0 software; SPSS Inc., Chicago, USA), and the significance level was set at $P<0.05\left(^{*}\right), P<0.01\left(^{* *}\right)$, and $P<0.001\left(^{* * *}\right)$ for all tests.

\section{Results}

3.1. Molecular Weight and Amino Acid Contents. HPLC gel filtration chromatography was used to evaluate the molecular weight. HPLC profile of collagen of deer sinew (DS) was shown in Figure 1(a); HPLC profiles of collagen peptide of DS were shown in Figure 1(b). There was a linear relation between the retention time and the log of the molecular mass of the reference proteins in the range of 669000-3323 Da $(y=$ $\left.-0.1840 x+7.8414, r^{2}=0.9934\right)$. Molecular size distributions with HPLC of collagen peptide were showed in Table 1. Collagen of DS was mainly distributed between 17,000 and

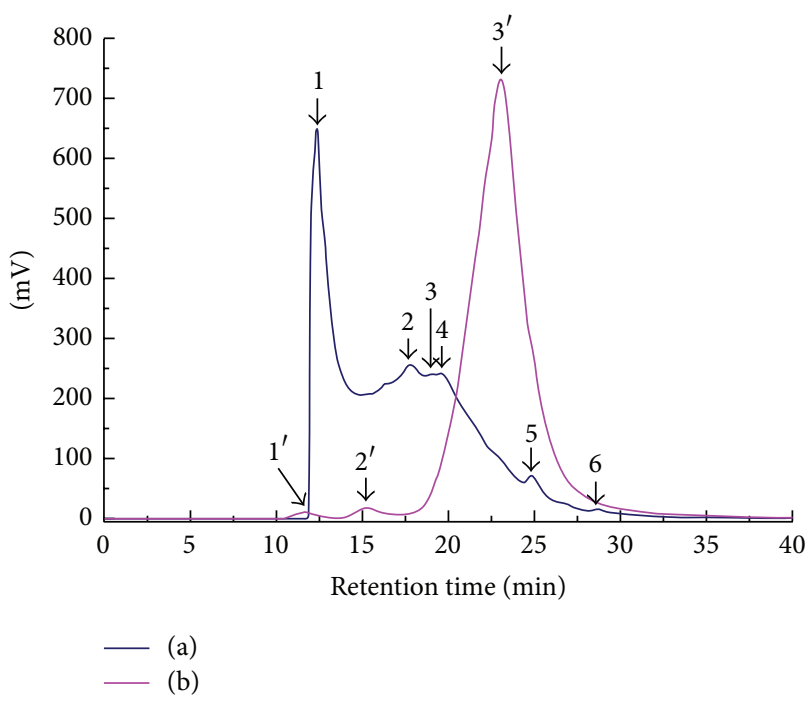

FIGURE 1: HPLC profiles of collagen peptide of deer sinew. Note: (a) collagen of deer sinew was extracted in boiling water. (b) Collagen peptide was treated with trypsin $(1: 1000, \mathrm{w} / \mathrm{w})$ at $37^{\circ} \mathrm{C}$ for $3 \mathrm{~h}$ after boiling water.

$367,000 \mathrm{Da}$. After trypsin enzymolysis for $3 \mathrm{~h}$, about $98 \%$ of the total collagen peptide was about the 4,000 Da.

As shown in Table 2, the collagen peptide contained seven essential amino acids: lysine, leucine, phenylalanine, threonine, valine, isoleucine, and methionine. Total content of the hydrophobic amino acids was $38.28 \%$. Glycine $(32.81 \%)$ was the major component in the amino acids of collagen peptide. Proline and hydroxyproline accounted for $14.59 \%$ and $6.99 \%$ of the total amino acid residues, respectively. Tyrosine, methionine, and histidine were lowest in the amino acids of collagen peptide.

3.2. Bone Mineral Density. Bone loss was evident at the femur sites in ovariectomized control (OVX) mice compared with age matched sham-operated (SHAM) at the end of the study. The results showed that the bone mineral density (BMD) of femur was significantly decreased by $14.49 \%$ in OVX $(0.301 \pm 0.018)$ as compared with the SHAM $(0.352 \pm 0.020)$ (Figure 2). The results showed that the administration of collagen peptide had antiosteoporotic effect, and OVX $+\mathrm{H}$, $\mathrm{OVX}+\mathrm{M}$, and OVX $+\mathrm{L}$ groups significantly recovered the BMD of OVX rats by $10.03 \%, 10.75 \%$, and $9.50 \%$, respectively. 
TABLE 2: Amino acid composition of collagen peptide.

\begin{tabular}{lc}
\hline Amino acid & Content $(\%)$ \\
\hline Gly & 32.81 \\
Ala & 14.80 \\
Pro & 14.59 \\
Hyp & 6.99 \\
Arg & 6.94 \\
Lys & 5.47 \\
Glu & 3.18 \\
Leu & 2.97 \\
Phe & 2.47 \\
Asp & 2.40 \\
Ser & 2.14 \\
Val & 1.88 \\
Thr & 1.53 \\
Ile & 0.87 \\
Tyr & 0.37 \\
Met & 0.33 \\
His & 0.28 \\
\hline
\end{tabular}

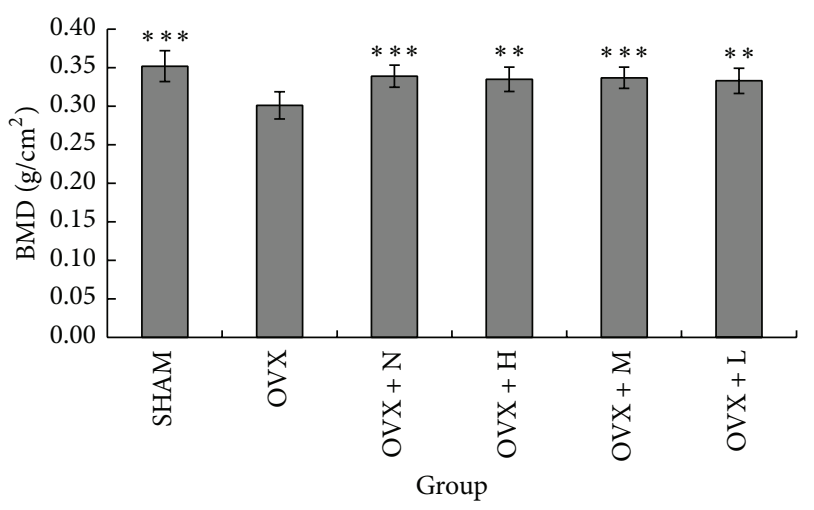

Figure 2: BMD for all the groups after 13 weeks of treatment. Note: ${ }^{* *} P<0.01$ and ${ }^{* * *} P<0.001$ compared with OVX group.

3.3. Body and Uterine Weight. The changes in the body weights of the rats in each group were shown in Figure 3. After surgery, four groups of rats had a similar initial mean body weight. The administration of collagen peptide and OVX groups had significantly greater weight gain than rats in the SHAM and OVX $+\mathrm{N}$ after the age of 25 weeks. As shown in Figure 4, at the end of the experiments, the body weight of rats in the OVX group $(381.8 \pm 27.96)$ was $20.33 \%$ higher than that of the SHAM rats $(317.3 \pm 23.95)$. The administration of collagen peptide $(0.4,0.2$, and $0.1 \mathrm{~g} / \mathrm{kg} / \mathrm{day})$ could not prevent the increase of body weight associated with $\mathrm{E}_{2}$ deficiency, while the nylestriol (1.0 mg/kg/week) could significantly prevent weight gain. The uterine weight of OVX rats was significantly decreased relative to SHAM (Figure 4), indicating the success of the surgical procedure. Collagen peptide $(0.4,0.2$, and $0.1 \mathrm{~g} / \mathrm{kg} /$ day $)$ treatment did not affect the uterine weight of OVX rats, while uterine weight of

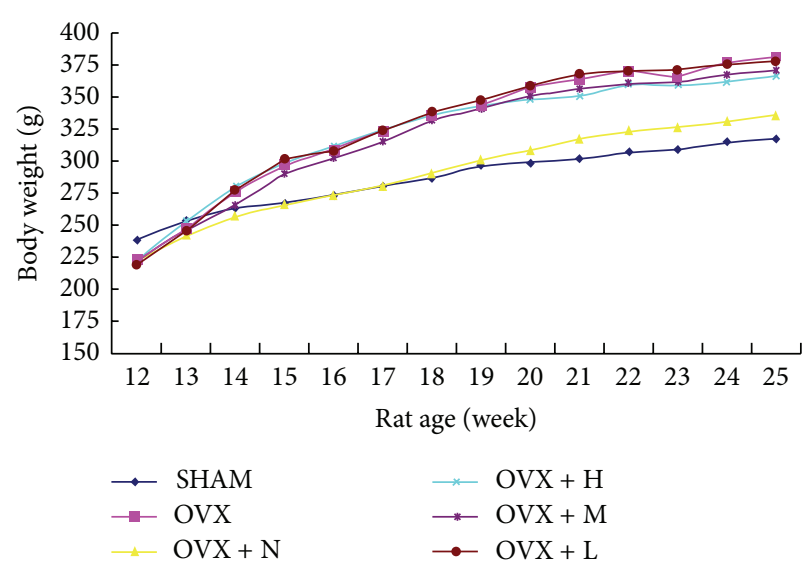

FIGURE 3: The changes in body weight in each group during 13 weeks.

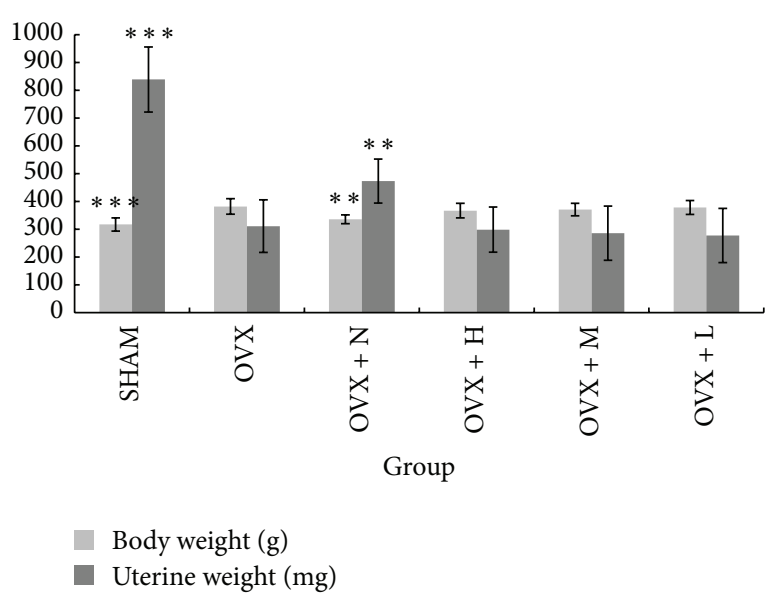

FIGURE 4: Body and uterine weight in different treatment groups after 13 weeks. Note: ${ }^{* *} P<0.01$ and ${ }^{* * *} P<0.001$ compared with OVX group.

the OVX $+\mathrm{N}$ group was significantly increased against those of OVX group.

3.4. Serum Biochemical Marker. Table 3 showed ovariectomy-induced significant changes in the serum biochemical marker. Compared with SHAM rats, OVX for 13 weeks significantly increased serum calcium $(\mathrm{Ca})$ by $7.63 \%$, phosphorus (P) by $14.10 \%$, alkaline phosphatase (ALP) by $31.72 \%$, hydroxyproline (Hyp) by $8.91 \%$, and reduced serum estradiol $\left(\mathrm{E}_{2}\right)$ by $61.95 \%$. Compared with OVX group, the collagen peptide $(0.4 \mathrm{~g} / \mathrm{kg} /$ day $)$ significantly decreased levels of serum Ca, P, and ALP; the collagen peptide $(0.4,0.2$, and $0.1 \mathrm{~g} / \mathrm{kg} /$ day) did not affect the levels of serum $\mathrm{E}_{2}$, while nylestriol (1.0 mg/kg/week) significantly increased the levels of serum $\mathrm{E}_{2}$ by $59.98 \%$; the contents of Hyp were remarkably increased in the administration of collagen peptide, because the collagen peptide was hydrolyzed to break down into its compont parts in the body. The results showed that the high $(0.4 \mathrm{~g} / \mathrm{kg} /$ week $)$ dose of collagen peptide had marked improvement for most of serum biochemical markers. 
TABLE 3: Effects of collagen peptide on serum biochemical markers in ovariectomized rats $(n=10)$.

\begin{tabular}{|c|c|c|c|c|c|}
\hline \multirow[b]{2}{*}{ Group } & \multicolumn{5}{|c|}{ Target } \\
\hline & $\begin{array}{c}\mathrm{Ca} \\
(\mathrm{mmol} / \mathrm{L})\end{array}$ & $\begin{array}{c}\mathrm{P} \\
(\mathrm{mmol} / \mathrm{L})\end{array}$ & $\begin{array}{l}\text { ALP } \\
(\mathrm{U} / \mathrm{L})\end{array}$ & $\begin{array}{c}\mathrm{E}_{2} \\
(\mathrm{pg} / \mathrm{mL})\end{array}$ & $\begin{array}{c}\text { Hyp } \\
(\mu \mathrm{g} / \mathrm{mL})\end{array}$ \\
\hline Sham & $2.36 \pm 0.13^{* *}$ & $1.56 \pm 0.12^{* *}$ & $82.43 \pm 12.47^{* *}$ & $26.99 \pm 6.08^{* * *}$ & $28.86 \pm 2.19^{*}$ \\
\hline OVX & $2.54 \pm 0.11$ & $1.78 \pm 0.15$ & $108.58 \pm 16.96$ & $10.27 \pm 2.65$ & $31.43 \pm 1.78$ \\
\hline $\mathrm{OVX}+\mathrm{N}$ & $2.43 \pm 0.12^{*}$ & $1.65 \pm 0.11^{*}$ & $93.64 \pm 10.38^{*}$ & $16.43 \pm 3.62^{* *}$ & $29.75 \pm 1.98$ \\
\hline $\mathrm{OVX}+\mathrm{H}$ & $2.43 \pm 0.11$ & $1.65 \pm 0.07^{*}$ & $94.68 \pm 11.35^{*}$ & $10.06 \pm 3.54$ & $37.43 \pm 2.96^{* * *}$ \\
\hline $\mathrm{OVX}+\mathrm{M}$ & $2.41 \pm 0.14$ & $1.70 \pm 0.09$ & $97.33 \pm 10.68$ & $10.31 \pm 4.05$ & $36.68 \pm 3.29^{* *}$ \\
\hline $\mathrm{OVX}+\mathrm{L}$ & $2.45 \pm 0.10$ & $1.69 \pm 0.15$ & $94.22 \pm 15.53$ & $10.04 \pm 4.06$ & $34.38 \pm 4.14$ \\
\hline
\end{tabular}

Note: ${ }^{*} P<0.05,{ }^{* *} P<0.01$, and ${ }^{* * *} P<0.001$ compared with OVX group.

TABLE 4: Effects of collagen peptide on bone mechanics indicators in ovariectomized rats $(n=10)$.

\begin{tabular}{|c|c|c|c|c|}
\hline \multirow[b]{2}{*}{ Group } & \multicolumn{4}{|c|}{ Target } \\
\hline & $\begin{array}{c}L_{\max } \\
(\mathrm{N})\end{array}$ & $\begin{array}{l}D_{\max } \\
(\mathrm{mm})\end{array}$ & $\begin{array}{r}B_{\max } \\
(\mathrm{N})\end{array}$ & $\begin{array}{c}\sigma \\
\left(\mathrm{N} / \mathrm{mm}^{2}\right)\end{array}$ \\
\hline Sham & $132.20 \pm 26.49^{* *}$ & $0.79 \pm 0.26^{*}$ & $661.00 \pm 132.47^{* *}$ & $123.90 \pm 23.17^{*}$ \\
\hline OVX & $91.80 \pm 17.99$ & $0.54 \pm 0.17$ & $459.00 \pm 89.93$ & $95.70 \pm 23.00$ \\
\hline $\mathrm{OVX}+\mathrm{N}$ & $121.80 \pm 8.99^{* *}$ & $0.73 \pm 0.23$ & $609.00 \pm 44.96^{* *}$ & $137.68 \pm 27.51^{*}$ \\
\hline $\mathrm{OVX}+\mathrm{H}$ & $114.60 \pm 16.08^{*}$ & $0.71 \pm 0.13^{*}$ & $573.000 \pm 80.42^{*}$ & $120.28 \pm 36.19$ \\
\hline $\mathrm{OVX}+\mathrm{M}$ & $110.40 \pm 21.63^{*}$ & $0.63 \pm 0.19$ & $552.00 \pm 108.17^{*}$ & $108.60 \pm 19.85$ \\
\hline OVX + L & $100.80 \pm 22.33$ & $0.58 \pm 0.10$ & $504.00 \pm 111.67$ & $109.63 \pm 31.13$ \\
\hline
\end{tabular}

Note: ${ }^{*} P<0.05$ and ${ }^{* *} P<0.01$ compared with OVX group.

3.5. Bone Mechanics Indicators. As shown in Table 4, the maximum load $\left(L_{\max }\right)$, maximum deflection $\left(D_{\max }\right)$, maximum bending moment $\left(B_{\max }\right)$, and bone stress $(\sigma)$ were significantly decreased by $30.56,31.65,30.56$, and $22.76 \%$, respectively, in OVX as compared with SHAM. Compared with OVX group, the OVX $+\mathrm{H}$ group significantly increased $L_{\max }, D_{\max }$, and $B_{\max }$; the OVX $+\mathrm{M}$ group increased $L_{\max }$ and $B_{\max }$. The collagen peptide $(0.4,0.2$, and $0.1 \mathrm{~g} / \mathrm{kg} /$ day $)$ treatment did not affect the $\sigma$ of OVX rats. The aforementioned results indicated that collagen peptide $(0.4 \mathrm{~g} / \mathrm{kg} / \mathrm{day})$ could significantly improve the bone mechanics indicators of OVX groups.

3.6. Bone Histomorphometric Parameters. Table 5 and Figure 5 showed significant changes in the femur microstructure and parameters. Compared with SHAM rats, OVX significantly reduced trabecular numbers (Tb.N) by $75 \%$, trabecular thickness (Tb.Th) by $3.52 \%$, trabecular bone volume (TV/BV) by $44.57 \%$, and cortical bone thickness (Cb.Th) by $2.13 \%$ and increased trabecular separation (Tb.Sp) by $73.05 \%$. By administering collagen peptide $(0.4,0.2$, and $0.1 \mathrm{~g} / \mathrm{kg} /$ day), the Tb.N, Tb.Th, TV/BV, and Cb.Th were increased significantly, but Tb.Sp was markedly reduced compared to OVX groups.

\section{Discussion}

The ovariectomized (OVX) rat is a well-known osteoporosis model, because the mechanism of controlling the gain and loss of bone mass is similar to human. Bone mineral density
(BMD) is considered to be the standard measure for the diagnosis of osteoporosis and the assessment of fracture risk, which can respond to the bone mass. Postmenopausal bone loss is characterized by a decrease in BMD and a microarchitecture deterioration of trabecular bone, with a particular diminution in the total number of trabecular and an increase in the number of their perforations [25]. Shuster [17] reported that a loss of collagen in skin and bones with aging was the causal counterpart to loss of bone density in senile osteoporosis. According to results of experiment, the collagen peptide supplement significantly increased the $\mathrm{BMD}$ of the femur in ovariectomized rats (Figure 2). The trabecular numbers (Tb.N), trabecular thickness (Tb.Th), cortical bone thickness (Cb.Th), and trabecular bone volume (BV/TV) were increased, while trabecular separation (Tb.Sp) was decreased in the OVX $+\mathrm{H}$ group (Table 5). These results show that collagen peptide supplement can reduce the bone turnover and improve the trabecular bone microarchitecture.

A marked atrophy of the uterus has been used as evidence of the success of ovariectomy, and it has been reported that estrogen deficiency following ovariectomy increased body weight [26], which had been postulated to be associated with regulatory effect of estrogen on the adipose tissue [27]. Our experimental results indicated that ovariectomy also led to a dramatic decrease in uterine weight (Figure 4) and levels of serum estradiol $\left(\mathrm{E}_{2}\right)$ (Table 3 ) and increase in body weight (Figure 4), while the administration of collagen peptide did not reverse the changes. So, it is suggested that the collagen peptide does not influence the actions of estrogen or its receptor. 
TABLE 5: Effects of collagen peptide on bone histomorphometric parameters in ovariectomized rats $(n=10)$.

\begin{tabular}{|c|c|c|c|c|c|}
\hline \multirow[b]{2}{*}{ Group } & \multicolumn{5}{|c|}{ Target } \\
\hline & $\begin{array}{c}\text { Tb.N } \\
(n)\end{array}$ & $\begin{array}{l}\text { Tb.Th } \\
(\mu \mathrm{m})\end{array}$ & $\begin{array}{l}\text { Tb.Sp } \\
(\mu \mathrm{m})\end{array}$ & $\begin{array}{c}\text { TV/BV } \\
(\%)\end{array}$ & $\begin{array}{c}\text { Cb.Th } \\
(\mu \mathrm{m})\end{array}$ \\
\hline SHAM & $3.60 \pm 0.70^{* * *}$ & $8.25 \pm 0.16^{* *}$ & $9.50 \pm 1.03^{* * *}$ & $36.64 \pm 3.27^{* * *}$ & $12.21 \pm 0.14^{* *}$ \\
\hline OVX & $0.90 \pm 0.32$ & $7.96 \pm 0.20$ & $16.44 \pm 1.51$ & $20.31 \pm 4.17$ & $11.95 \pm 0.11$ \\
\hline $\mathrm{OVX}+\mathrm{N}$ & $1.70 \pm 0.67^{*}$ & $8.12 \pm 0.12$ & $12.95 \pm 1.92^{* *}$ & $25.36 \pm 4.58^{*}$ & $12.15 \pm 0.21^{*}$ \\
\hline $\mathrm{OVX}+\mathrm{H}$ & $1.70 \pm 0.48^{* *}$ & $8.13 \pm 0.13^{*}$ & $12.68 \pm 0.65^{* * *}$ & $27.28 \pm 1.94^{* *}$ & $12.12 \pm 0.19^{* *}$ \\
\hline $\mathrm{OVX}+\mathrm{M}$ & $1.60 \pm 0.52^{*}$ & $8.11 \pm 0.17$ & $13.09 \pm 1.16^{* * *}$ & $26.58 \pm 2.24^{* *}$ & $12.11 \pm 0.24$ \\
\hline OVX + L & $1.60 \pm 0.52^{* *}$ & $8.17 \pm 0.17$ & $13.27 \pm 0.87^{* * *}$ & $26.36 \pm 2.26^{* *}$ & $12.14 \pm 0.24$ \\
\hline
\end{tabular}

Note: ${ }^{*} P<0.05,{ }^{* *} P<0.01$, and ${ }^{* * *} P<0.001$ compared with OVX group.

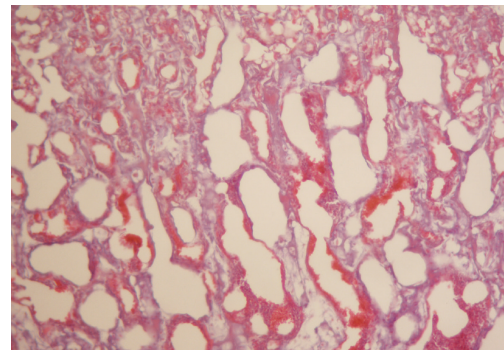

(a)

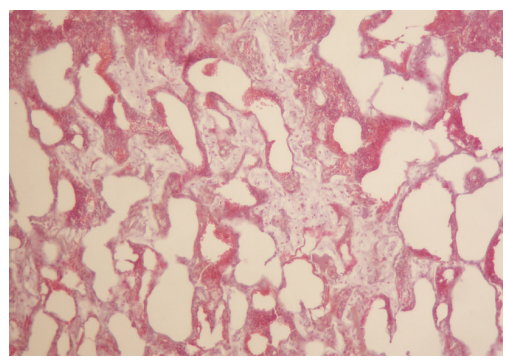

(d)

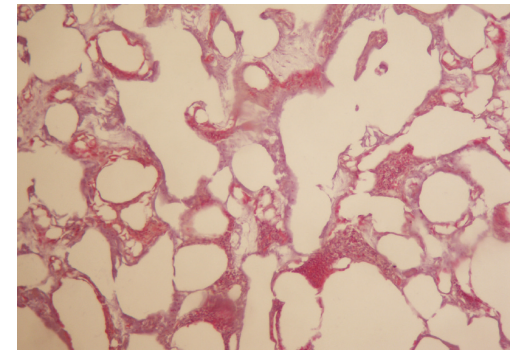

(b)

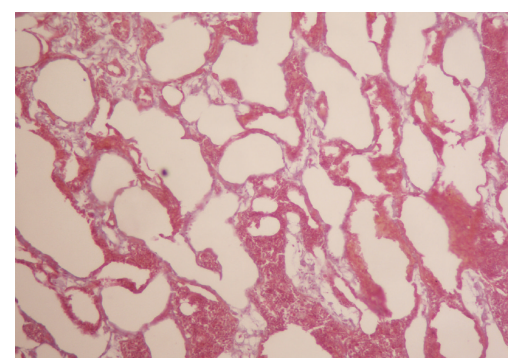

(e)

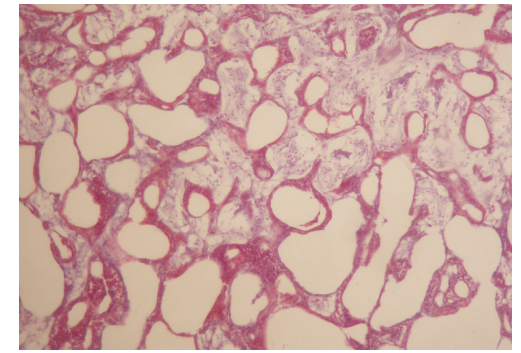

(c)

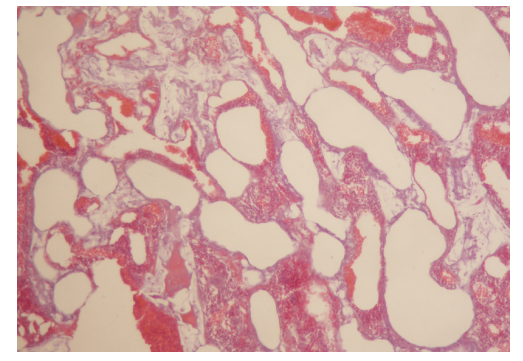

(f)

FIGURE 5: Photomicrographs of trabecular bone. Note: undecalcified section (100x magnification) shows trabecular bone using multifunction true color pathological image analyzer. (a) SHAM, (b) OVX, (c) OVX + N, (d) OVX + H, (e) OVX + M, and (f) OVX + L.

Calcium $(\mathrm{Ca})$ and phosphorus $(\mathrm{P})$ are required for normal skeletal growth and mineralization and play an important role in regulating bone remodeling and bone mass. $\mathrm{Ca}$ is a naturally occurring hormone that acts to inhibit bone resorption by decreasing osteoclast activity [7]. P or acidic amino acids contained in collagen peptide could selectively bind calcium and facilitate $\mathrm{Ca}$ transports across the intestinal membranes [28]. Ovariectomy-related bone loss also decreased contents of bone $\mathrm{Ca}$ and $\mathrm{P}$ and increased contents of serum $\mathrm{Ca}$ and $\mathrm{P}$, while the administration of collagen peptide $(0.4 \mathrm{~g} / \mathrm{kg} /$ day $)$ decreased levels of serum $\mathrm{Ca}$ and $\mathrm{P}$ against that of the OVX (Table 3). We speculate that collagen peptide supplement could promote collagen synthesis and inhibit loss of Ca and P. ALP is the biochemical marker of bone turnover, affects osteoid formation and mineralization, and is still the most widely used in clinical practice [29]. During bone resorption, highly active osteoclasts may secrete factors into the space between the cell and bone surface such as acid, matrix metalloproteinases (MMPS), and cathepsin
$\mathrm{K}$ in excess that can degrade collagen type I into Hyp [1]. Our results supported the notion that, compared with SHAM group, the content of Hyp significantly increased in the OVX group, because the collagen peptide is hydrolyzed to break down into Hyp in the body.

Whole-bone stiffness and strength show a function of total bone mass, the tissue geometric distribution, and material properties [30]. The estrogenic deficit caused by bilateral oophorectomy resulted in a loss of bone mass, with a consequent decrease in bone mechanics indicators (Table 4), and the reduced concentration of bone collagen reducible cross-links also was associated with reduced bone strength [31,32]. Our experimental results show that collagen peptide can enhance the bone biomechanical properties of ovariectomized rats.

Bone is a living dynamic metabolic system which is made up of approximately $70 \%$ inorganic salts and $30 \%$ organic matrix by weight; however, collagen (mostly type I collagen) makes up over $90 \%$ of the organic component. It is actually 
collagen that generates the bone density that gives our bones the ability to withstand stress. Collagen is a protein that provides a framework of soft tissue which calcium adheres onto, creating a hardened framework. Calcium is still an important player, but, without enough collagen, taking large doses can be wasteful. Several studies have demonstrated that bone loss increased postmenopausal osteoporosis, the resorption of the organic matrix over formation. The decreased rate of collagen synthesis may also lead to a change in the quality of collagen fibers, which weakens them. After menopause, hormonal and systemic factors may also directly or indirectly modify type I collagen properties, such as collagen degradation [31], overhydroxylation, and poor cross-linking [33,34]. So, collagen plays an important role in therapy of osteoporosis. Deer sinew (DS) is widely used for many years in China to strengthen tendons and bones. Sun et al. [22] reported that collagen isolated from DS ameliorated Freund's adjuvant (CFA) induced adjuvant arthritis by reducing serum IL-1 $\beta$ and TNFa inflammatory cytokines. Collagen of DS prevented retinoic acid induced osteoporosis by increasing BMD and improving bone mechanics indicators and bone histomorphometric parameters [21]. Our experiments show that administration of collagen peptide of DS significantly affects the skeletal system of ovariectomized rats, counteracts some changes induced by estrogen deficiency, and also induced changes which seem to be unrelated to typical estrogenic effects in rats with decreased estrogen levels. Although collagen peptide has been considered as therapeutic agent of treat bone diseases, it remains unknown whether collagen peptide modulates bone metabolism or not.

The sequence of collagen is predominantly repeats of the Gly-X-Y triplet, where X can be any other amino acid but is usually a proline, and $\mathrm{Y}$ is often a hydroxyproline. Collagen is constituted by three polypeptide chains that form a triple helix structure. The average molecular weight of one chain amounts to about $90 \mathrm{kDa}$. Our results showed that content of amino acid of collagen peptide complied with the amino acid composition (Table 2). Because of large molecular weight, collagen is difficult to be absorbed by body. Enzymatic hydrolysis of collagen is one approach used to release bioactive protein and is widely applied to improve functional and nutritional properties of collagen sources. The researches showed that collagen peptides of less than $3000 \mathrm{Da}$ molecular weight could be readily absorbed by gastrointestinal tract [35]. It appeared in the human blood party in a small peptide form $[36,37]$ and was accumulated in skin for up to $96 \mathrm{~h}$ [38]. Collagen peptides have been reported to perform strong antioxidant activities $[39,40]$. However, low molecular weight collagen peptide (about $4000 \mathrm{Da}$ ) from DS accounted for 98\% (Table 1). Collagen hydrolysate has long been used in pharmaceuticals and food supplements for improving skin and bone tissues [19]. Administering shark skin gelatin to the ovariectomized rats resulted in the bone mineral density of the femur epiphysis being higher than that in the sham-operated rats. The contents of type I collagen and glycosaminoglycan in the epiphysis were increased by administering shark skin gelatin [41]. Han et al. [42] reported that the cod bone gelatin treatment prevented bone loss by decreasing bone resorption in OVX rats with established osteopenia and it might also exert its action through modulation of RANKL and OPG expression and suppression of proinflammatory cytokines release, which in turn were important for the consequent osteoclastogenesis. The vertebrae of the ovariectomized group that received the higher dosage of collagen hydrolysates withstood a load four times greater and exhibited higher levels of protein and osteocalcin content than those receiving either gelatin or no supplement, and, at the same time, these results supported the notion that supplementing the normal diet of castrated female rats with 10 times the amount of $\mathrm{CH}$ suggested for humans can have a protective effect on the loss of mass, total protein, and physical strength of the rodent's bone system [43]. These studies have shown that gelatin hydrolysate or collagen peptides may be effective in minimizing bone loss in OVX rats.

As a conclusion, collagen peptide from deer sinew can inhibit the progression of bone loss induced by ovariectomy in rats. The potential antiosteoporotic mechanism conjectured that collagen peptide provides a plenty of glycine, proline, and other amino acids to accelerate collagen synthesis, and collagen peptide has the antioxidative activity to reduce the intercellular free radicals to protect the osteoblasts. We believe that collagen peptide may be useful in human for the prevention of not only postmenopausal osteoporosis but also osteoporosis in general. Further studies are required to determine its antiosteoporotic mechanism of action for the prevention and treatment of osteoporosis.

\section{Conflict of Interests}

The authors declare that there is no conflict of interests regarding the publication of this paper.

\section{Acknowledgments}

This research was supported by Ministry of Science and Technology (2011BAI03B02-2) and National Natural Science Foundation of China (81303165).

\section{References}

[1] V. R. Jagtap and J. V. Ganu, "Effect of antiresorptive therapy on urinary hydroxyproline in postmenopausal osteoporosis," Indian Journal of Clinical Biochemistry, vol. 27, no. 1, pp. 90-93, 2012.

[2] P. D. Delmas, "Biochemical markers of bone turnover for the clinical investigation of osteoporosis," Osteoporosis International, vol. 3, no. 1, pp. 81-86, 1993.

[3] Y. Kuo, F. Tsuang, J. Sun et al., "Calcitonin inhibits SDCPinduced osteoclast apoptosis and increases its efficacy in a rat model of osteoporosis," PLoS ONE, vol. 7, no. 7, Article ID e40272, 2012.

[4] M. R. McClung, P. Geusens, P. D. Miller et al., "Effect of risedronate on the risk of hip fracture in elderly women," The New England Journal of Medicine, vol. 344, no. 5, pp. 333-340, 2001.

[5] J.-H. Cho, D.-C. Cho, S.-H. Yu, Y.-H. Jeon, J.-K. Sung, and K.-T. Kim, "Effect of dietary calcium on spinal bone fusion in 
an ovariectomized rat model," Journal of Korean Neurosurgical Society, vol. 52, no. 4, pp. 281-287, 2012.

[6] M. Maricic, J. D. Adachi, S. Sarkar, W. Wu, M. Wong, and K. D. Harper, "Early effects of raloxifene on clinical vertebral fractures at 12 months in postmenopausal women with osteoporosis," Archives of Internal Medicine, vol. 162, no. 10, pp. 1140-1143, 2002.

[7] T. M. Hisel and B. B. Phillips, "Update on the treatment of osteoporosis," Formulary, vol. 38, no. 4, pp. 223-243, 2003.

[8] L. Devareddy, D. A. Khalil, B. J. Smith et al., "Soy moderately improves microstructural properties without affecting bone mass in an ovariectomized rat model of osteoporosis," Bone, vol. 38, no. 5, pp. 686-693, 2006.

[9] G. Zhang, L. Qin, W. Y. Hung et al., "Flavonoids derived from herbal Epimedium Brevicornum Maxim prevent OVXinduced osteoporosis in rats independent of its enhancement in intestinal calcium absorption," Bone, vol. 38, no. 6, pp. 818-825, 2006.

[10] W. Zhang, T. Fujikawa, K. Mizuno et al., "Eucommia leaf extract (ELE) prevents OVX-induced osteoporosis and obesity in rats," The American Journal of Chinese Medicine, vol. 40, no. 4, pp. 735-752, 2012.

[11] M. Liu, G. G. Xiao, P. Rong et al., "Therapeutic effects of radix dipsaci, pyrola herb, and cynomorium songaricum on bone metabolism of ovariectomized rats," BMC Complementary and Alternative Medicine, vol. 12, article 67, 2012.

[12] P. C. Leung, E. C. H. Ko, S. W. S. Siu, E. S. Y. Pang, E. L. Y. Wong, and K. F. Cheng, "Developing an effective health supplement for the prevention of osteoporosis," International Journal of Osteoporosis and Metabolic Disorders, vol. 5, no. 1, pp. 1-12, 2012.

[13] D. W. Lim and Y. T. Kim, "Dried root of Rehmannia glutinosa prevents bone loss in ovariectomized rats," Molecules, vol. 18, no. 5, pp. 5804-5813, 2013.

[14] K. Oh, S. Kim, J. Kim et al., "Effect of Rehmannia glutinosa Libosch extracts on bone metabolism," Clinica Chimica Acta, vol. 334, no. 1-2, pp. 185-195, 2003.

[15] C. Kim, H. Ha, J. Lee, J. Kim, K. Song, and S. W. Park, "Herbal extract prevents bone loss in ovariectomized rats," Archives of Pharmacal Research, vol. 26, no. 11, pp. 917-924, 2003.

[16] H. Zhang, Y. Zhao, Y. F. Xu et al., "Study on the condition of trypsinase hydrolyzing deer tendons collagen," Food Science and Technology, vol. 35, no. 9, pp. 216-218, 2010.

[17] S. Shuster, "Osteoporosis, a unitary hypothesis of collagen loss in skin and bone," Medical Hypotheses, vol. 65, no. 3, pp. 426432, 2005.

[18] S. Viguet-Carrin, P. Garnero, and P. D. Delmas, "The role of collagen in bone strength," Osteoporosis International, vol. 17, no. 3, pp. 319-336, 2006.

[19] E. Proksch, D. Segger, J. Degwert, M. Schunck, V. Zague, and S. Oesser, "Oral supplementation of specific collagen peptides has beneficial effects on human skin physiology: a double-blind, placebo-controlled study," Skin Pharmacology and Physiology, vol. 27, no. 1, pp. 47-55, 2013.

[20] H. Zhang, Y. Zhao, Y. F. Xu, and Y. L. Lin, "Study on effects of collagen of deer bone on osteoporosis in ovariectomized rats," Pharmacology and Clinics of Chinese Materia Medica, vol. 27, no. 5, pp. 76-79, 2011.

[21] H. Zhang, Y. Zhao, Y. Li, X. Sun, X. Bai, and D. Zhao, "Effects of deer tendons collagen on osteoporosis rats induced by retinoic acid," Journal of Chinese Medicinal Materials, vol. 33, no. 3, pp. 411-414, 2010.
[22] X. D. Sun, Y. Q. Li, and Y. Zhao, "Therapeutic effect of the deer tendons collagen on adjuvant arthritis in rats," China Journal of Chinese Materia Medica, vol. 34, no. 23, pp. 3135-3138, 2009.

[23] E. P. Palacio, S. S. Müller, T. Sardenberg et al., "Detecting early biomechanical effects of zoledronic acid on femurs of osteoporotic female rats," Journal of Osteoporosis, vol. 2012, Article ID 162806, 8 pages, 2012.

[24] Z. Hayatullina, N. Muhammad, N. Mohamed, and I. Soelaiman, "Virgin coconut oil supplementation prevents bone loss in osteoporosis rat model," Evidence-Based Complementary and Alternative Medicine, vol. 2012, Article ID 237236, 8 pages, 2012.

[25] L. Xue, Y. Wang, Y. Jiang et al., "Comparative effects of ErXian Decoction, Epimedium herbs, and icariin with estrogen on bone and reproductive tissue in ovariectomized rats," Evidencebased Complementary and Alternative Medicine, vol. 2012, Article ID 241416, 11 pages, 2012.

[26] S. Hidaka, Y. Okamoto, K. Miyazaki, and T. Uesugi, "Evaluation of a soybean product Fujiflavone P40 as an antiosteoporotic agent in rats," Phytotherapy Research, vol. 17, no. 2, pp. 112-119, 2003.

[27] Y. Nishikawa, H. Ikegami, M. Sakata et al., "Ovariectomy increases the level of estrogen receptor mRNA and estrogen receptor binding sites in female rat adipose tissue," Journal of Endocrinological Investigation, vol. 16, no. 8, pp. 579-583, 1993.

[28] S. Hidaka, Y. Okamoto, S. Uchiyama et al., "Royal jelly prevents osteoporosis in rats: beneficial effects in ovariectomy model and in bone tissue culture model," Evidence-Based Complementary and Alternative Medicine, vol. 3, no. 3, pp. 339-348, 2006.

[29] F. R. Singer and D. R. Eyre, "Using biochemical markers of bone turnover in clinical practice," Cleveland Clinic Journal of Medicine, vol. 75, no. 10, pp. 739-750, 2008.

[30] J. H. Cole and M. C. H. van der Meulen, "Whole bone mechanics and bone quality," Clinical Orthopaedics and Related Research, vol. 469, no. 8, pp. 2139-2149, 2011.

[31] H. Oxlund, L. Mosekilde, and G. Ortoft, "Reduced concentration of collagen reducible cross links in human trabecular bone with respect to age and osteoporosis," Bone, vol. 19, no. 5, pp. 479-484, 1996.

[32] M. Saito and K. Marumo, "Collagen cross-links as a determinant of bone quality: a possible explanation for bone fragility in aging, osteoporosis, and diabetes mellitus," Osteoporosis International, vol. 21, no. 2, pp. 195-214, 2010.

[33] H. Hoshino, M. Takahashi, K. Kushida, T. Ohishi, and T. Inoue, "Urinary excretion of type I collagen degradation products in healthy women and osteoporotic patients with vertebral and hip fractures," Calcified Tissue International, vol. 62, no. 1, pp. 36-39, 1998.

[34] M. Saito, K. Fujii, S. Soshi, and T. Tanaka, "Reductions in degree of mineralization and enzymatic collagen cross-links and increases in glycation-induced pentosidine in the femoral neck cortex in cases of femoral neck fracture," Osteoporosis International, vol. 17, no. 7, pp. 986-995, 2006.

[35] L. Wang, Q. Ma, J. Cheng, B. Guo, and H. Yue, "Portal absorption of feed oligo-peptides in chickens," Asian-Australasian Journal of Animal Sciences, vol. 17, no. 9, pp. 1277-1280, 2004.

[36] H. Ohara, H. Matsumoto, K. Ito, K. Iwai, and K. Sato, "Comparison of quantity and structures of hydroxyprolinecontaining peptides in human blood after oral ingestion of gelatin hydrolysates from different sources," Journal of Agricultural and Food Chemistry, vol. 55, no. 4, pp. 1532-1535, 2007.

[37] K. Iwai, T. Hasegawa, Y. Taguchi et al., "Identification of food-derived collagen peptides in human blood after oral 
ingestion of gelatin hydrolysates," Journal of Agricultural and Food Chemistry, vol. 53, no. 16, pp. 6531-6536, 2005.

[38] S. Oesser, M. Adam, W. Babel, and J. Seifert, "Oral administration of 14C labeled gelatin hydrolysate leads to an accumulation of radioactivity in cartilage of mice (C57/BL)," The Journal of Nutrition, vol. 129, no. 10, pp. 1891-1895, 1999.

[39] A. Alemán, E. Pérez-Santín, S. Bordenave-Juchereau, I. Arnaudin, M. C. Gómez-Guillén, and P. Montero, "Squid gelatin hydrolysates with antihypertensive, anticancer and antioxidant activity," Food Research International, vol. 44, no. 4, pp. 1044-1051, 2011.

[40] E. Mendis, N. Rajapakse, and S. Kim, "Antioxidant properties of a radical-scavenging peptide purified from enzymatically prepared fish skin gelatin hydrolysate," Journal of Agricultural and Food Chemistry, vol. 53, no. 3, pp. 581-587, 2005.

[41] Y. Nomura, K. Oohashi, M. Watanabe, and S. Kasugai, "Increase in bone mineral density through oral administration of shark gelatin to ovariectomized rats," Nutrition, vol. 21, no. 11-12, pp. 1120-1126, 2005.

[42] X. Han, Y. Xu, J. Wang et al., "Effects of cod bone gelatin on bone metabolism and bone microarchitecture in ovariectomized rats," Bone, vol. 44, no. 5, pp. 942-947, 2009.

[43] E. de Almeida Jackix, F. Cúneo, J. Amaya-Farfan, J. V. de Assunção, and K. D. Quintaes, "A food supplement of hydrolyzed collagen improves compositional and biodynamic characteristics of vertebrae in ovariectomized rats," Journal of Medicinal Food, vol. 13, no. 6, pp. 1385-1390, 2010. 


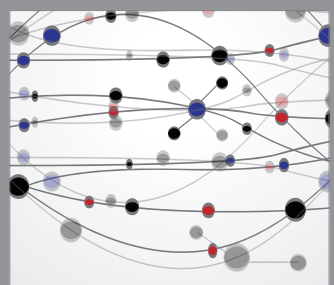

The Scientific World Journal
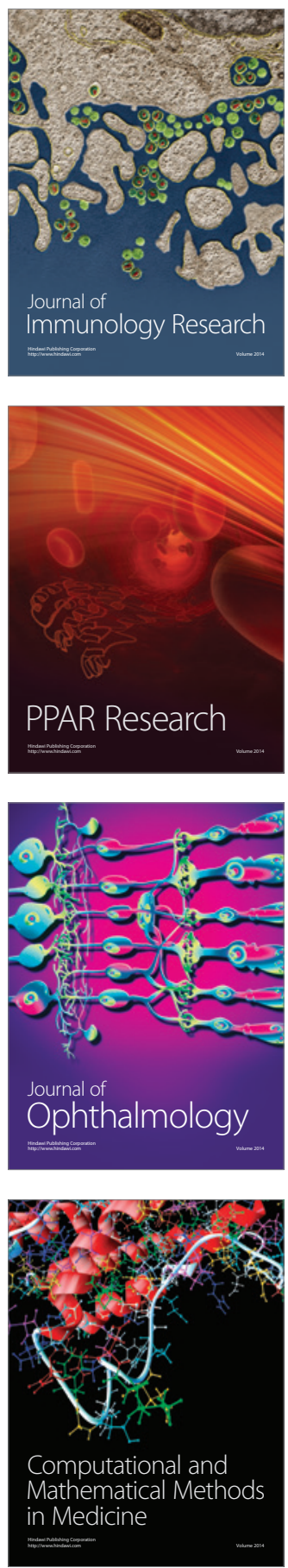

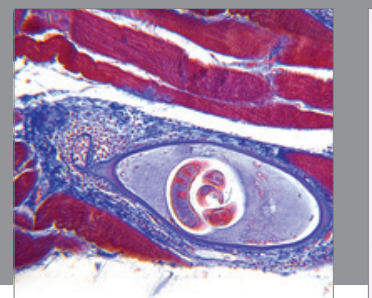

Gastroenterology

Research and Practice
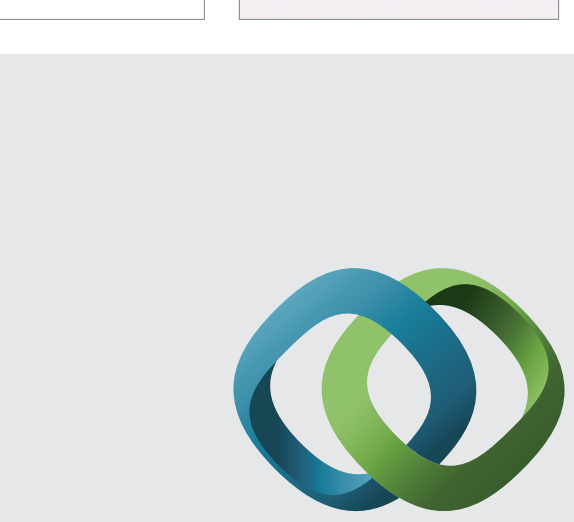

\section{Hindawi}

Submit your manuscripts at

http://www.hindawi.com
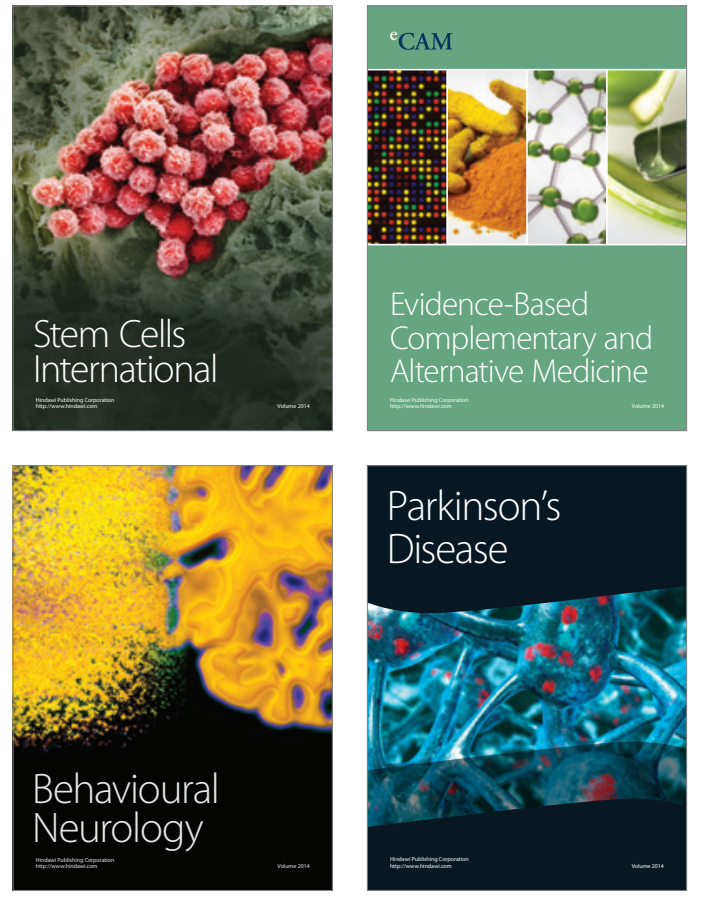
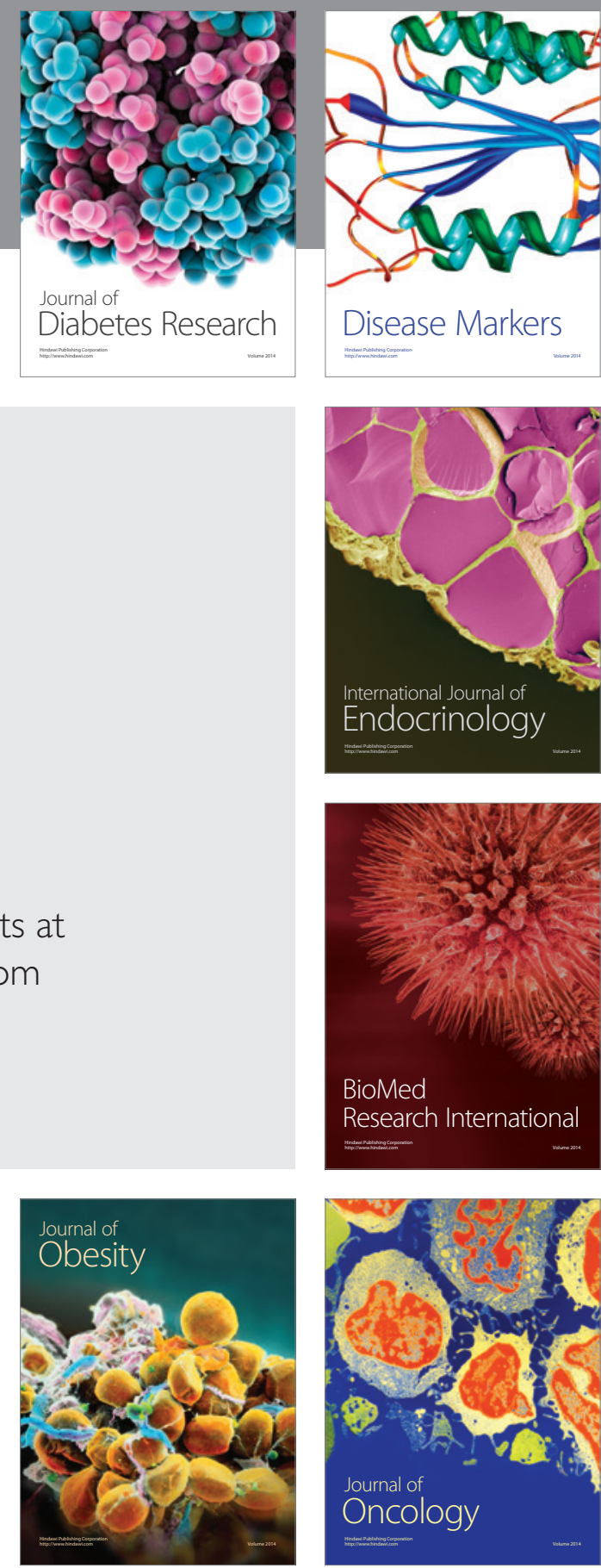

Disease Markers
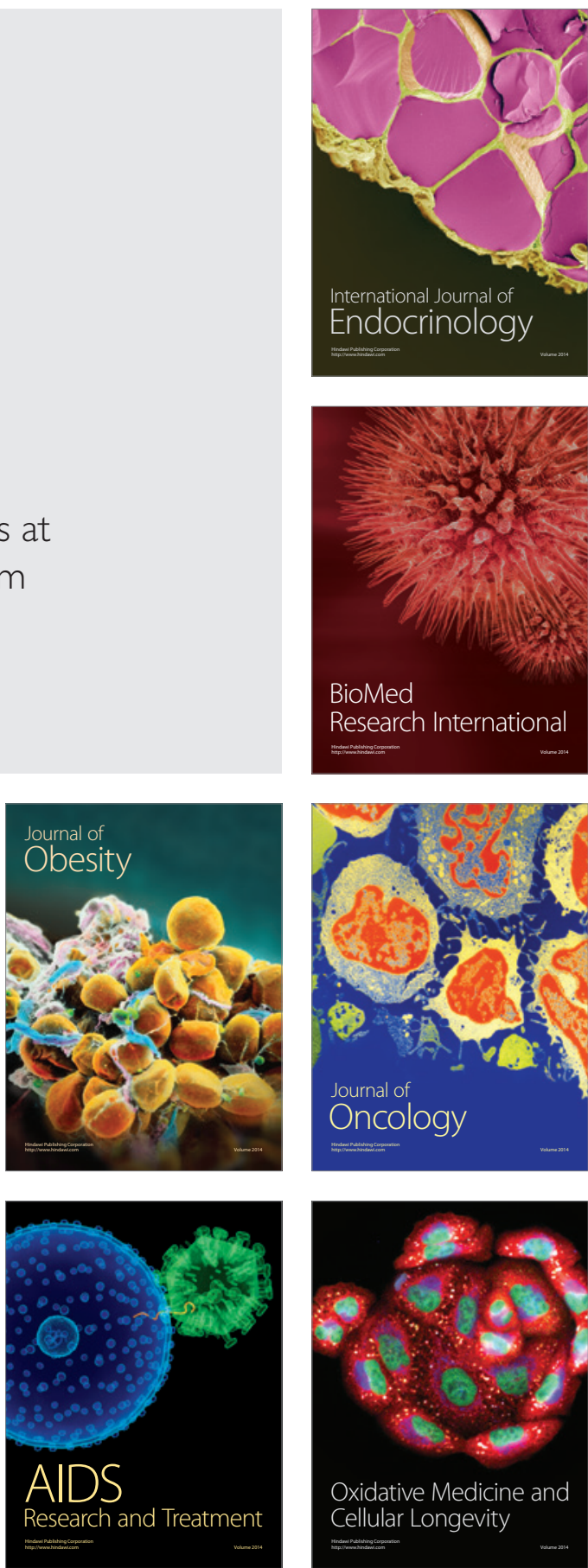